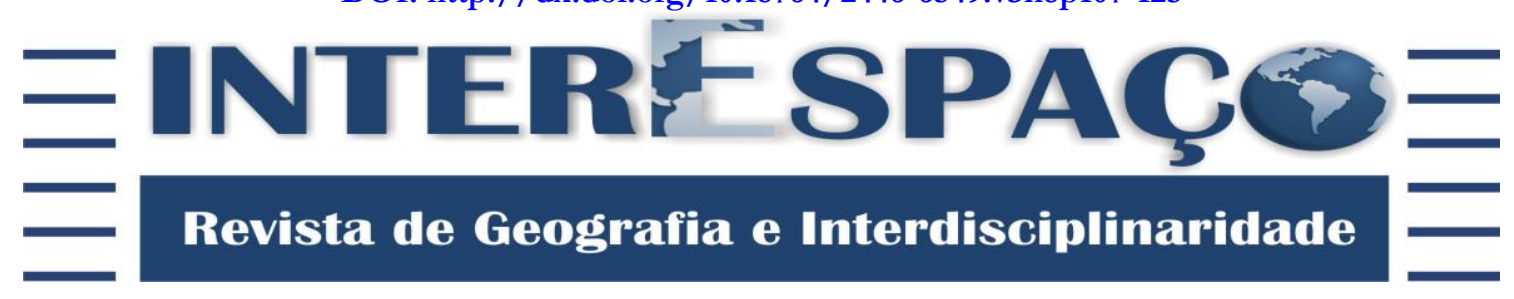

\title{
PLUVIÔMETRO DE BAIXO CUSTO E A VARIAÇÃO DA CHUVA NO MUNICÍPIO DE BARRA DO GARÇAS - MT (OUTUBRO DE 2015 A ABRIL DE 2016)
}

\author{
LOW COST RAIN GAUGES AND RAINFALL VARIABILITY IN BARRA DO \\ GARÇAS - MT (OCTOBER 2015 TO APRIL 2016)
}
PLUVIÓMETRO DE BAJO COSTO Y LA VARIACIÓN DE LA LLUVIA EN EL MUNICIPIO DE BARRA DO GARÇAS - MT
(OCTUBRE DE 2015 A ABRIL 2016)

\author{
Romário Rosa de Sousa \\ Mestre em Geografia pela Universidade Federal de Mato Grosso - UFMT. Professor do \\ Departamento de Geografia da Universidade Federal de Mato Grosso - UFMT/Campus do \\ Araguaia. \\ romarioufg@yahoo.com.br
}

Recebido para avaliação em 19/02/2017; Aprovado para publicação em 07/04/2017.

\section{RESUMO}

Este trabalho teve como objetivo principal confeccionar e distribuir vinte pluviômetros de baixo custo de PVC, dentro do município de Barra do Garças-MT, onde posteriormente a partir dos dados coletados, gerou-se um mapa pluviométrico da irregularidade da chuva. Os trabalhos metodológicos foram desenvolvidos em onze etapas distintas. Após toda a fase de aquisição dos materiais de baixo custo, na sequência realizou-se os seguintes procedimentos: confecção dos pluviômetros, aferição, instalação, treinamento dos produtores rurais, coleta de dados a campo, organização dos dados em planilha eletrônica com geração de relatório de tabela dinâmica, realização do processo de interpolação dos dados, geração do mapa pluviométrico, ajustes e finalização do mapa gerado, análise e discussão dos dados. É importante ressaltar que o processo de interpolação dos dados foi realizado no software ArcGis, 10.1. Ressalta-se que o processo de construção do pluviômetro de baixo custo, demonstrou que foi de grande ajuda, no sentido de baixar custos com um instrumento de grande importância para o meio rural e urbano. Também ficou comprovado que o pluviômetro de baixo custo, é um aparelho de credibilidade e confiabilidade nos registros dos dados pluviométricos. Quanto a distribuição pluviométrica da chuva no município de Barra do Garças-MT, foi bem diversificada e irregular para o período estudado, onde averiguou-se que o maior acumulo pluviométrico foi registrado no extremo sul do município com 986,1 mm de chuva. E encontra partida um núcleo seco com um baixo volume de precipitação foi confirmado na porção leste com 146,2 $\mathrm{mm}$ de chuva.

Palavras-chave: Pluviômetros; Chuva; PVC; Baixo Custo.

\section{ABSTRACT}

This study aims to design, assemble and distribute twenty low cost PVC rain gauges in Barra do Garças-MT, where afterwards a rainfall map was generated from the collected data. The methodological works were developed in eleven distinct stages. Following the entire acquisition phase of the low cost materials, the following procedures were carried out: preparation of the rain gauges, gauging, installation, training of rural producers, data collection in the field, data organization in electronic spreadsheet making a dynamic table report, data interpolation, creating a rainfall map, adjustment and finalization of the created map, data analysis and discussion. It is 
important to note the data interpolation process was performed in ArcGis software, 10.1. It should be noted that the process of construction of the low cost rain gauge showed that it was of great help in order to reduce costs with an instrument of great importance for the rural and urban environments. It has also been proven that the low cost rain gauge is an apparatus of credibility and reliability in rainfall records. As for the rainfall distribution in Barra do Garças-MT, it was well diversified and irregular for the period studied, where it was verified that the highest rainfall accumulation was recorded in the southern end of the municipality with $986.1 \mathrm{~mm}$ of rain. However, finding a dry core with a low volume of precipitation was confirmed in the eastern portion with $146.2 \mathrm{~mm}$ of rain.

Keywords: Rain Gauges; Rain; PVC; Low Cost.

\section{RESUMEN}

Este trabajo tuvo como objetivo principal elaborar, montar y distribuir veinte pluviómetros de bajo costo de PVC, dentro del municipio de Barra do Garças-MT, posteriormente, a partir de los datos colectados, se originó un mapa pluviométrico de la irregularidad de la lluvia. Los trabajos metodológicos fueron desarrollados en once etapas distintas. Después de toda la fase de adquisición de los materiales de bajo costo, en seguida se realizaron los siguientes procedimientos: confección de los pluviómetros, calibración, instalación, entrenamiento de los productores rurales, colecta de datos a campo, organización de los datos en planilla electrónica con elaboración de un informe de tabla dinámica, realización del proceso de interpolación de los datos, producción del mapa pluviométrico, ajustes y finalización del mapa generado, análisis y discusión de los datos. Es importante realzar que el proceso de interpolación de los datos fueron realizados en el software ArcGis, 10.1. Se resalta que el proceso de construcción del pluviómetro de bajo costo, demostró que fue de gran ayuda, en el sentido de bajar costos con un instrumento de gran importancia para el medio rural y urbano. También quedó demostrado que el pluviómetro de bajo costo, es un aparato de credibilidad y confiabilidad en los registros de los datos pluviométricos. Cuanto a la distribución pluviométrica en el municipio de Barra do Garças-MT, fue bien diversificada e irregular para el periodo estudiado, donde se comprobó que el mayor acúmulo pluviométrico fue registrado en el extremo Sur del municipio con 986,1mm de lluvia. En contra partida un núcleo seco con un bajo volumen de precipitación fue confirmado en la región Este con 146,2 mm de lluvia.

Palabras-clave: Pluviómetros; Lluvia; PVC; Bajo Costo.

\section{INTRODUÇÃO}

Para Pereira et al. (2002), nas regiões tropicais, a chuva, ou precipitação pluvial, é a forma principal pela qual a água retorna da atmosfera para a superfície terrestre após os processos de evaporação e condensação, completando, assim, o ciclo hidrológico. A quantidade e a distribuição de chuvas que ocorrem anualmente em uma região determinam o tipo de vegetação natural e também o tipo de exploração agrícola possível.

Procurar entender a dinâmica das chuvas, segundo Vila (1975), é algo tão antigo quanto à própria civilização. Há registros de trabalhos feitos pelos chineses, antes de Cristo e, posteriormente ao longo da trajetória humana, tornou-se cada vez mais frequente o interesse de conhecer melhor os fatores e elementos climáticos. A exemplo disso existem relatos que guerreiros no período medieval eram incumbidos de ficarem observando as aproximações das nuvens nas imediações dos castelos ao longo dos cultivos, e tendo os 
mesmos a incumbência de avisarem com antecedência da probabilidade de ocorrência de chuva no reino.

O conhecimento da distribuição e das variações pluviométricas tanto no tempo como no espaço é importante para os planejamentos agropecuário e dos recursos hídricos, e ainda, para estudos hidrológicos. Há algum tempo o homem reconhece a necessidade de incluir as variáveis do meio físico em estudos voltados para o planejamento do uso agrícola do solo, mas a dificuldade maior tem consistido em escolher as variáveis mais significativas e como reuni-las de forma a serem realmente válidas na aplicação ao planejamento regional.

Muitas vezes a distribuição irregular das chuvas atinge as culturas em sua fase reprodutiva, afetando a produção final. Desse modo, o conhecimento da distribuição espacial das chuvas em uma determinada região adquire uma grande importância econômica, uma vez que a sua frequência pode servir de orientação para que os agricultores ajam no sentido de minimizar possíveis reduções na produtividade das culturas.

Segundo Ayoade (1988), distribuição estacional e espacial da precipitação varia grandemente de um local para outro, dependendo do tipo predominante de formação da chuva, mas, em geral, a precipitação é máxima no Equador e decresce com o aumento da latitude. Entretanto, a irregularidade e orientação da precipitação média anual mostram que existem outros fatores que afetam mais efetivamente a sua distribuição geográfica do que a própria distância do Equador. Além disso, toda a zona intertropical é afetada por períodos de interrupção da precipitação que ocorrem durante a estação chuvosa, denominados regionalmente de veranico.

Para Ab’Saber (1950), a distribuição geográfica da chuva depende, basicamente, de quatro fatores: latitude, distância do oceano, ação do relevo e efeito das correntes marítimas. Se as chuvas fossem igualmente distribuídas no globo, a média seria de $900 \mathrm{~mm}$, porém há muito contrastes de uma latitude para outra.

A atmosfera é uma massa em contínuo movimento e isto induz variações nas condições meteorológicas predominantes em uma região. O estado da atmosfera pode ser descrito por variáveis que caracterizam sua condição energética (PEREIRA et al., 2002).

Embora os registros de precipitação possam sugerir uma tendência de aumentar ou diminuir, existe normalmente uma tendência de voltar à média; períodos úmidos, mesmo irregularmente, são sempre contrabalanceados por períodos secos. A regularidade dessas flutuações tem sido repetidamente investigada, mas, com exceção das variações diurnas e estacionais, nenhum ciclo regular significativo foi encontrado (VILLELA; MATOS, 1975). 
A distribuição estacional e espacial da precipitação varia grandemente de um local para outro, dependendo do tipo predominante da formação da chuva, podendo ser convectiva, orográfica ou frontal. Além disso, toda a zona intertropical é afetada por períodos de interrupção da precipitação que ocorrem durante a estação chuvosa. Este fenômeno é denominado regionalmente de "veranico".

Vários estudos têm sido realizados para determinar estas causas e os efeitos sobre a distribuição da precipitação, porém as conclusões são bastante desencontradas. As grandes flutuações observadas na precipitação mensal sugerem que as médias não constituem um bom índice para análise da oferta pluviométrica, principalmente porque estas médias estão associadas a coeficientes de variação que chegam a ultrapassar 100\% em alguns meses menos chuvosos (ASSAD et al., 1993).

Segundo Assad et al. (1993), o clima do Planalto Central é caracterizado por uma estação seca bem definida que se estende de maio a setembro. Esta característica pode ser de uma maneira geral uma ameaça para a atividade agrícola uma vez que o período se concentra chuvoso, de outubro a abril, quando ocorrem de 80 a 90\% do total anual das chuvas, em torno de $1600 \mathrm{~mm}$. Embora este total seja considerado suficiente para a maioria das culturas, a distribuição irregular das chuvas é inevitável e torna-se um dos fatores limitantes para a agricultura nesta região, acarretando a deficiência hídrica.

De maneira geral, o regime de chuvas de um local é caracterizado pela quantidade e distribuição de precipitação ocorrida em determinados meses ou estação do ano (ASSAD, 1994).

A atividade agrícola e o rendimento das colheitas dependem, fundamentalmente, da evolução das manifestações do tempo. Se este for desfavorável, a produção poderá ficar comprometida. Em razão disso, além do tipo de solo, as características climáticas são elementos fundamentais na escolha das culturas agrícolas em diversas partes do planeta (CONTI, 1988).

No intuito de conhecer a variação das chuvas e seu efeito espacial sobre o ambiente, foram confeccionados e distribuídos vinte pluviômetros de PVC, dentro do município de Barra do Garças-MT, onde posteriormente a partir dos dados coletados, gerou-se um mapa pluviométrico da irregularidade da chuva.

\section{METODOLOGIA}


| Pluviômetro de baixo custo e a variação da chuva no município de Barra do Garças - MT (outubro de 2015 a abril de 2016)|

| Romário Rosa de Sousa |

Foi definida, como área de estudo, a cidade de Barra do Garças - MT, localizada às margens do Rio Araguaia, no Estado de Mato Grosso, divisa com o Estado de Goiás. O Estado de Mato Grosso está localizado entre as coordenadas geográficas de latitudes $7^{\circ}$ a $18^{\circ}$ sul e longitudes $50^{\circ}$ a $62^{\circ}$ oeste de Greenwich, onde as altitudes variam de 100 a 1200 metros, no centro do Continente Sul Americano (Figura 1).

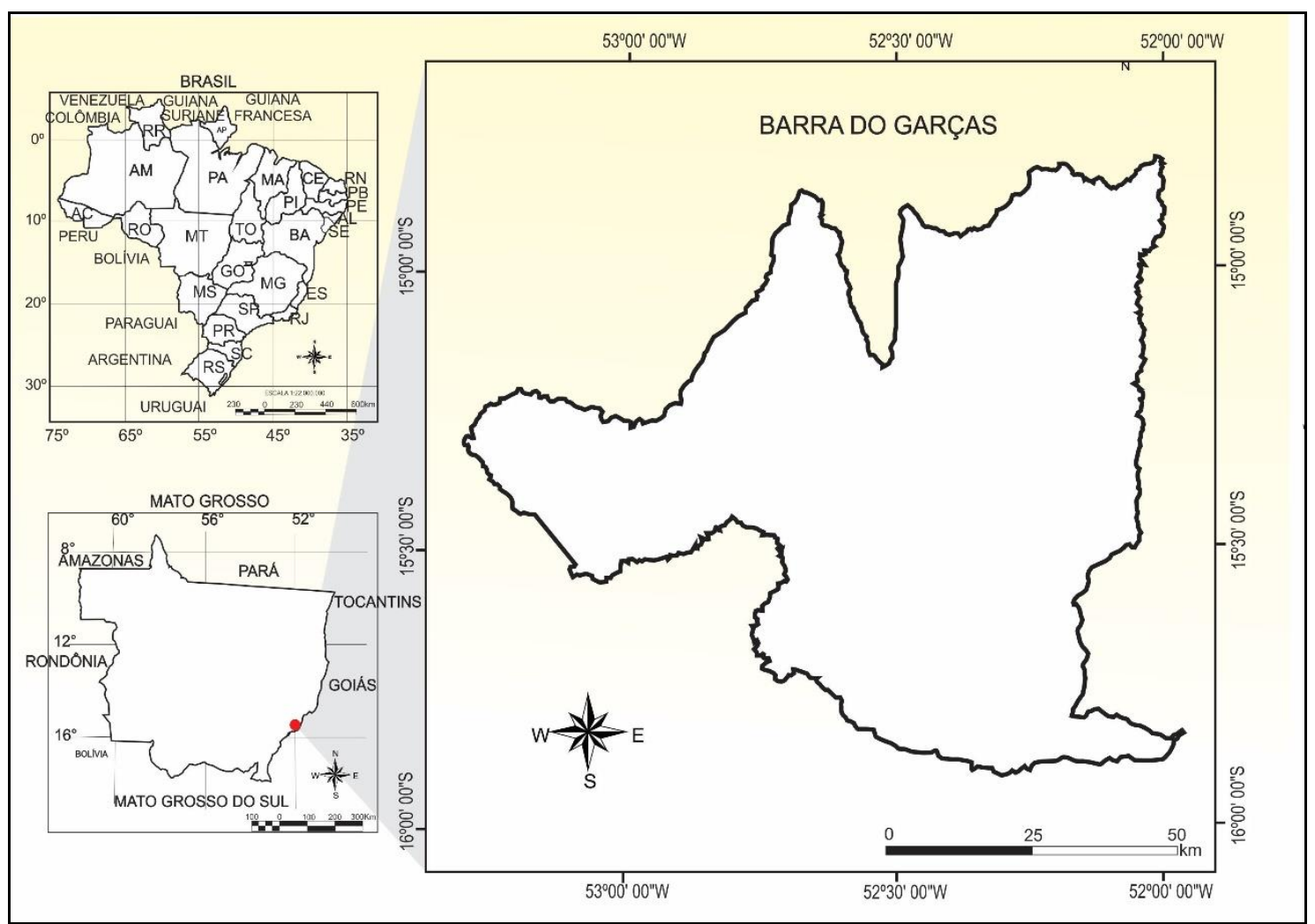

Figura 1 - Localização da área de estudo Elaboração: SOUSA, R. R., 2017.

A proposta deste projeto em monitoramento da chuva no município de Barra do Garças-MT, na montagem dos pluviômetros de PVC. Os trabalhos metodológicos foram desenvolvidos em 11(onze) etapas distintas, seguindo as orientações de Assunção (1997).

$1^{a}$ etapa: abordagem teórica, sobre o foi tema abordado;

$2^{a}$ etapa: aquisição dos materiais de custo;

$3^{a}$ etapa: montagem do kit de anotações das quantidades pluviométricas;

$4^{a}$ etapa: confecção, colagem e montagem dos pluviômetros de PVC de baixo custo;

$5^{a}$ etapa: teste de vazamento pluviômetros de PVC;

$\sigma^{a}$ etapa: preparação e conversão das provetas graduada de $250 \mathrm{ml}$ para $15 \mathrm{~mm}$;

$7^{a}$ etapa: processo de instalação dos pluviômetros de PVC, nas propriedades rurais do município de Barra do Garças-MT; 
| Pluviômetro de baixo custo e a variação da chuva no município de Barra do Garças - MT (outubro de 2015 a abril de 2016)|

| Romário Rosa de Sousa |

8 etapa: Coleta dos dados a campo e organização em dos mesmos em planilha eletrônica com extração de relatório de tabela dinâmica com os valores;

$9^{a}$ etapa: interpolação dos dados de chuva no software ArcGis, 10.2 com a licença do Laboratório de Geoinformação - Regional Jataí-Universidade Federal de Goiás, (Environmental Systems Research Institute - ESRI);

$10^{a}$ etapa: finalização e ajustes dos mapas gerados;

$11^{a}$ etapa: análise e discussão dos dados.

É importante ressaltar que na espacialização dos dados de precipitação foi utilizado o método Inverso do Quadrado da distância, do inglês Inverse Distance Weight (IDW), no Sistema de Informações Geográficas (SIG) no software ArcGIS 10.1, através da extenção Geostatistical Analyst, conforme empregado por Chang (2006), Souza et al. (2011) e Lobato et al. (2015). Vale ressaltar que existem inúmeros outros interpoladores que igualmente apresentam resultados satisfatórios como o aqui utilizado. O IDW é um método genuinamente matemático, segundo Miranda (2005), Souza et al. (2011), este procedimento estima um valor para um local não amostrado como uma média dos valores dos dados dentro de uma vizinhança. O cálculo da média é ponderada pela distância entre o ponto a ser interpolado e seus vizinhos, destaca-se que o peso da distância é ajustado por um expoente, isso implica que, quanto maior expoente, maior será a influência da distância.

\section{Materiais}

Para o bom desenvolvimento dos trabalhos fez-se uso dos seguintes materiais:

\begin{tabular}{|c|l|}
\hline Quantidade & \multicolumn{1}{|c|}{ Descrição } \\
\hline 20 & Apontador de plástico \\
\hline 20 & Bico de torneira de $1 / 2$ polegada de metal \\
\hline 20 & Borrachas escolar \\
\hline 20 & Lápis de madeira \\
\hline 20 & Mastro de madeira de $1,50 \mathrm{~cm}$ de comprimento por $4 \times \mathrm{x} 6 \mathrm{~cm}$ \\
\hline 20 & Níple de $1 / 2$ polegada \\
\hline 20 & Prancheta de madeira \\
\hline 20 & Provetas de $250 \mathrm{ml}$ \\
\hline 20 & Redução PVC de 150 x $100 \mathrm{~mm}$ \\
\hline 20 & Registro de esfera de $1 / 2$ polegada \\
\hline 01 & Resma de papel $\mathrm{A} 4$ \\
\hline 01 & Rolo de barbante de algodão \\
\hline 20 & Tampão de $100 \mathrm{~mm}$ \\
\hline 01 & Tubo de cola adesiva \\
\hline 01 & Tubo PVC de $75 \mathrm{~mm}$ \\
\hline 01 & Tubo de PVC $100 \mathrm{~mm}$ \\
\hline
\end{tabular}

Organizador: SOUSA, R. R., 2016. 
O desenvolvimento do presente trabalho é útil para empresas agrícolas, planejamento agropecuário, técnicos, pesquisadores, professores, agropecuaristas, empresas de insumos e defensivos agrícolas, defesa civil, ambientalistas e outros profissionais que necessitam conhecer o "raio x" pluviométrico do município de Barra do Garças, que tem o seu potencial essencialmente agropecuário, urbano, industrial e turístico.

\section{RESULTADOS E DISCUSSÃO}

Na região dos Cerrados é necessário um amplo estudo dos padrões de distribuições de chuva, ou seja, a definição de locais que tenham condições pluviométricas semelhantes e agrupá-los convenientemente, de acordo com técnicas estatísticas apropriadas, pois a simples média das informações não constitui um bom indicador do regime pluviométrico, daí a necessidade de sempre ampliar as informações sobre as chuvas nos Cerrados.

Os valores extremos de pluviometria são de grande importância, tanto em termos técnicos e científicos quanto econômicos. Suas aplicações estendem-se para quase todas as ciências ambientais e tem grande interesse no dimensionamento de obras de engenharia hidráulica, conservação do solo e em agricultura.

Assim entendemos que a toda a irregularidade da chuva pode gerar uma série de problemas no planejamento urbano e rural. Com isso, de acordo com Assad et al. (1994), a redução da oferta pluviométrica, associada à baixa capacidade de retenção de água de alguns solos dos Cerrados, como areias quartzosas e latossolos vermelho-amarelo, podem levar plantas cultivadas a atingirem rapidamente o ponto de murcha, reduzindo consequentemente a produtividade.

Numa época de grandes transformações ambientais, onde as alternâncias de períodos chuvosos e secos assumem proporções de calamidade, em função da intensidade da ocupação humana, quer nas atividades agrárias, ou nas aglomerações urbanas, torna-se inegável o controle das intervenções de natureza humana no meio ambiente (TROPPMAIR, 2002).

Aragão (2009) argumenta que concretamente a formação da vegetação, quer seja de florestas, Cerrado, gramíneas ou de deserto, está dependente das condições naturais do clima, principalmente da umidade relativa do ar e da chuva.

O bioma Cerrado predominantemente, característico do geo-sistema dos planaltos aplainados do Brasil Central, ocupava cerca de 1,7 milhão de $\mathrm{km}^{2}$, ou cerca de $20 \%$ do território brasileiro, deste total considera-se que $46 \%$ são aptos à produção agrícola, com 
base em lavouras de ciclo curta ou pecuária moderna, 34\% à exploração limitada com base em pecuária extensiva e 20\% deveriam ser preservados. Assim, os tipos fisionômicos da região de cerrados são: Mata de galeria ou ciliar, Mata mesofítica ou subcaducifólica de encosta, Mata de várzea, Cerradão, Cerrado stricto-sensu, Campo sujo, campo limpo ou hidromórfico e veredas (TARIFA, 1994).

Nos meses de maio, junho, julho, agosto e setembro a precipitação pode ser registrada com até $60 \mathrm{~mm}$, sendo esses meses que apresentam valores muito baixos à precipitação, apesar do elevado valor pluviometrico anual. Com isso, os baixos valores de umidade relativa do ar são rotineiros com obervações de 30\% (MONTEIRO, 1951).

Em contrapartida, no Cerrado os meses de novembro, dezembro, janeiro, fevereiro e março são os meses que apresentam os maiores valores de precipitação pluviométrica, com eventos chuvosos que somam praticamente todo o valor anual. A dinâmica pluviométrica pode ser variável de um lugar para o outro, dependendo de fatores regionais e locais (orientação e declividade), uma vez que a precipitação é função não só da massa de água contida no ar, mas também de sua velocidade e subida. Assim, para o Estado de Mato Grosso, o máximo pluviométrico se verifica no solstício de verão, ou seja, de dezembro, janeiro, fevereiro e março e o mínimo no solstício de inverno, ocorrendo no mês de julho, estando estes relacionados os eventos chuvosos a conjugação das correntes perturbadas de W, N e S, (VIANELLO 1986).

Através de software específico de edição gráfica, foi elaborada e impressa a planilha para anotações das quantidades pluviométricas (Figura 2). 


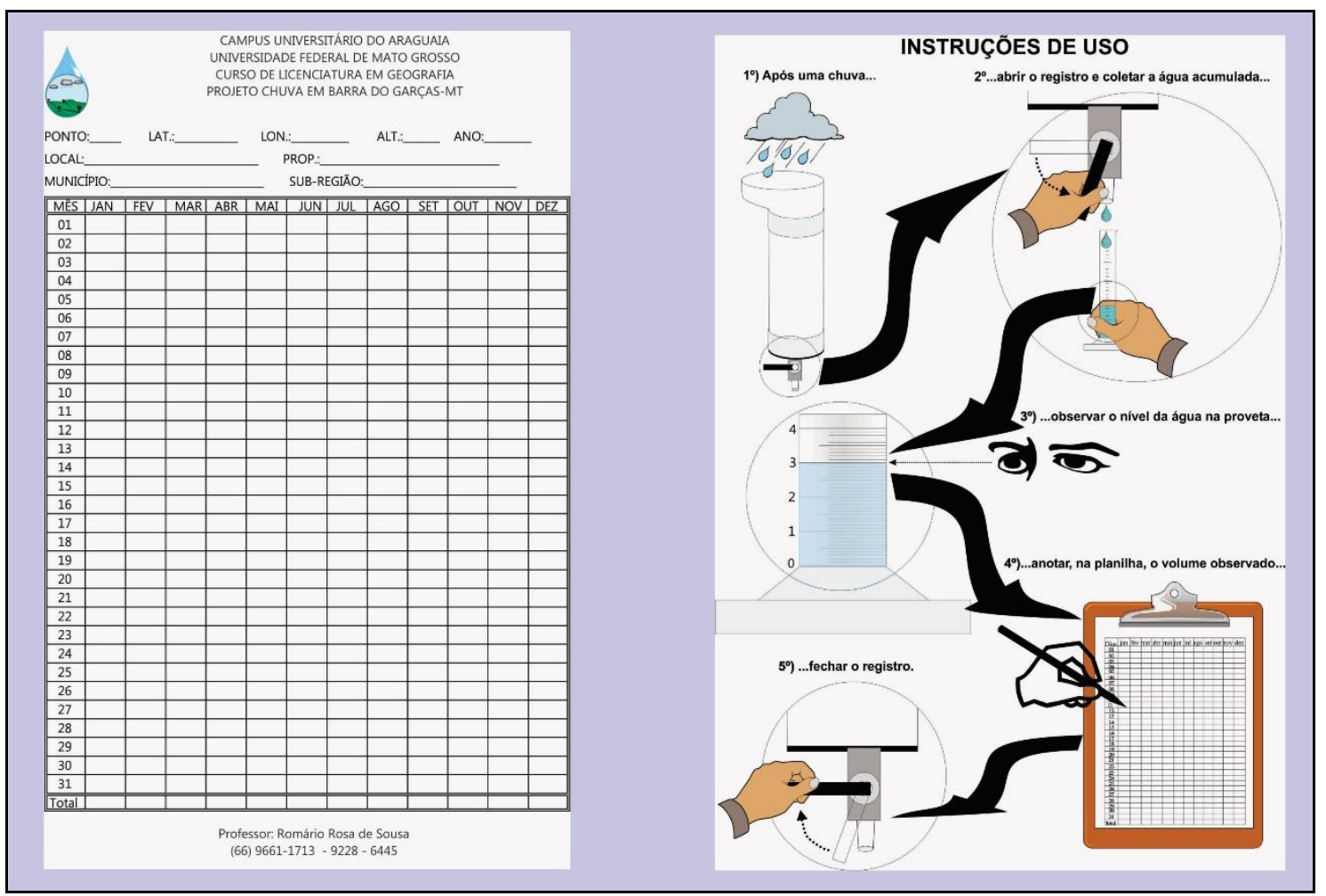

Figura 2 - Planilha para anotações pluviométricas - frente e verso Organização: SOUSA, R. R., 2015.

Na sequência do desenvolvimento dos trabalhos foi montado o kit de anotações dos dados pluviométricos, sendo prancheta, saco plástico de medindo $20 \mathrm{~cm} \times 30 \mathrm{~cm}$, lápis, borracha e apontador (Figura 3).

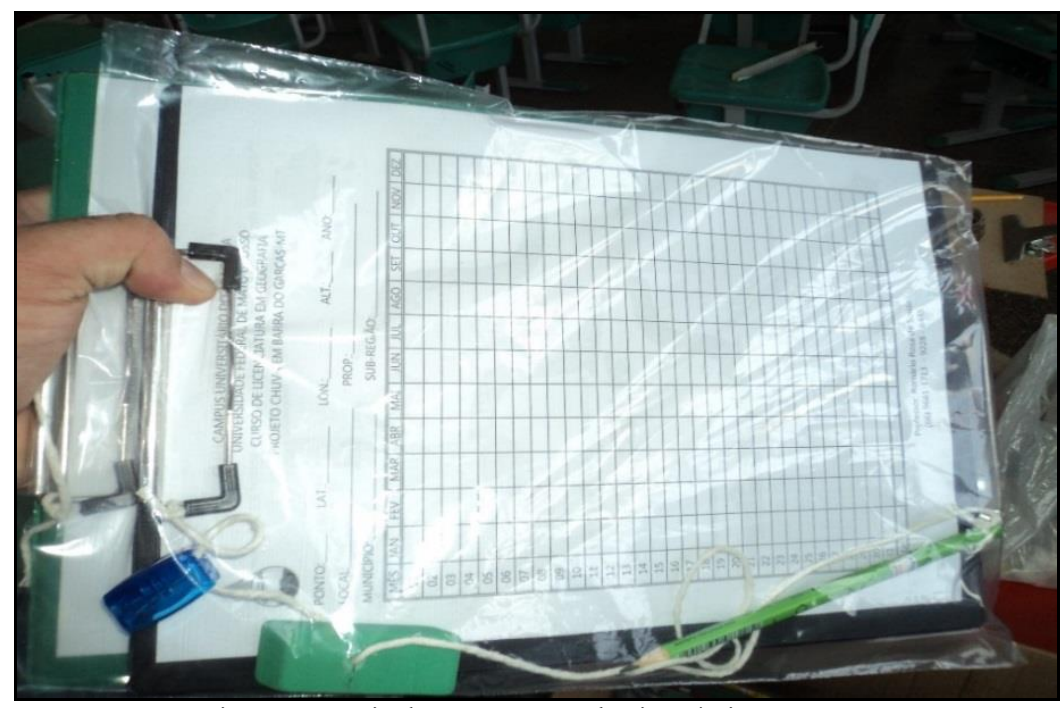

Figura 3 - Kit de anotações pluviométricas pronta Fonte: SOUSA, R. R., 2016. 
| Pluviômetro de baixo custo e a variação da chuva no município de Barra do Garças - MT (outubro de 2015 a abril de 2016)|

| Romário Rosa de Sousa |

Posteriormente à aquisição, procedeu-se e confecção dos pluviômetros de PVC, onde se iniciou com um furo de $1 / 2$ polegada na parte inferior da tampa de $100 \mathrm{~mm}$ (Figura 4), utilizando-se uma furadeira e um instrumento denominado serra copo.

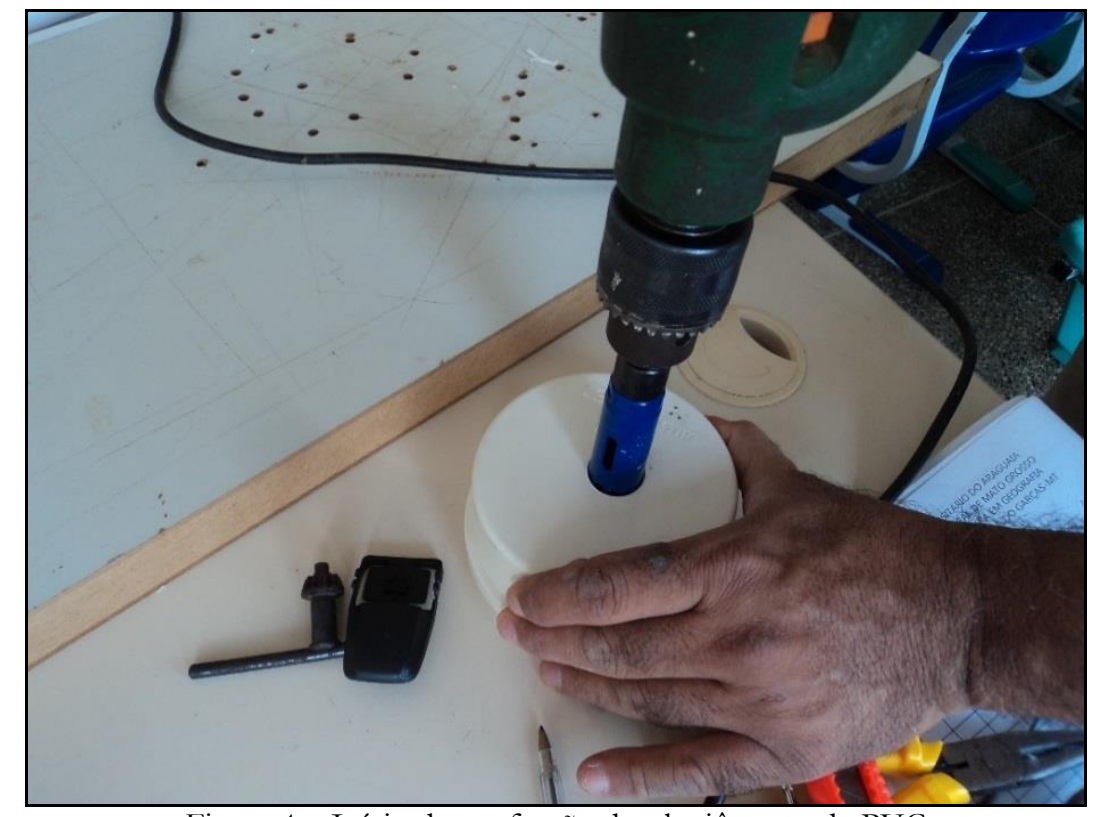

Figura 4 - Início da confecção do pluviômetro de PVC Fonte: SOUSA, R. R., 2016.

Logo em seguida, efetuaram-se os cortes de 50 centímetros de comprimento para cada pedaço do tubo de PVC, a ser destinado de reservatório hídrico do pluviômetro, já o próximo passo, realizou-se o processo de colagem das reduções em uma das extremidades do reservatório hídrico (Figuras 5 e 6).

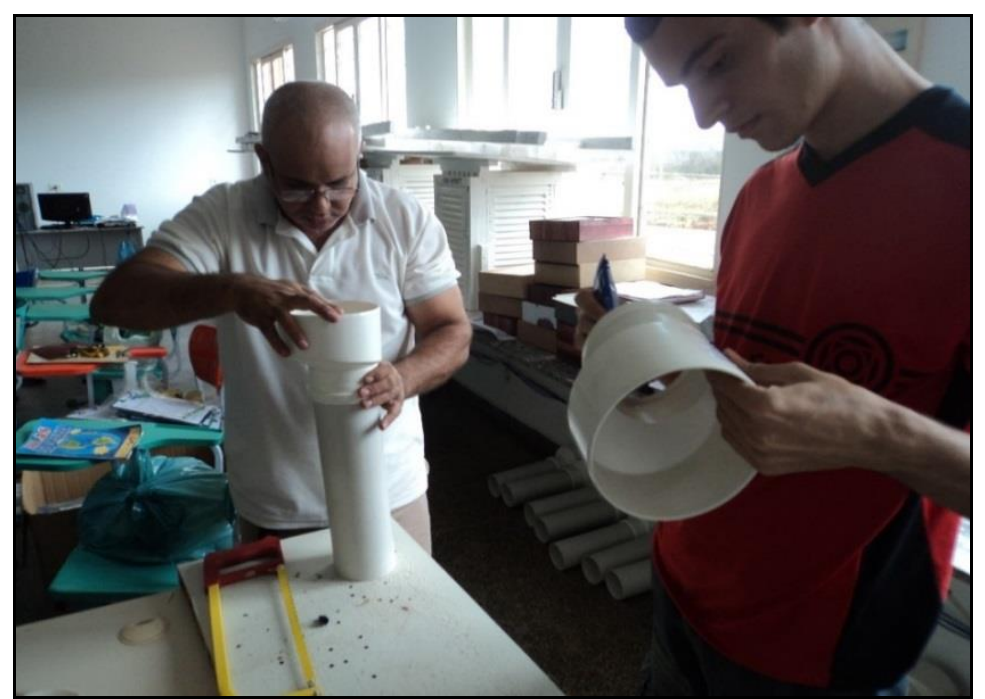

Figura 5 - Cortes e colagem do pluviômetro de PVC

Fonte: SOUSA, R. R., 2016. 
| Pluviômetro de baixo custo e a variação da chuva no município de Barra do Garças - MT (outubro de 2015 a abril de 2016)|

| Romário Rosa de Sousa |

A próxima etapa dos trabalhos pautou-se em fixar os registros de esfera com os bicos de torneiras, onde ambos colados e rosqueados no corpo rígido do pluviômetro. Confeccionou-se 20 pluviômetros de PVC, cada instrumento possui uma área de captação de $144 \mathrm{~km}^{2}$.

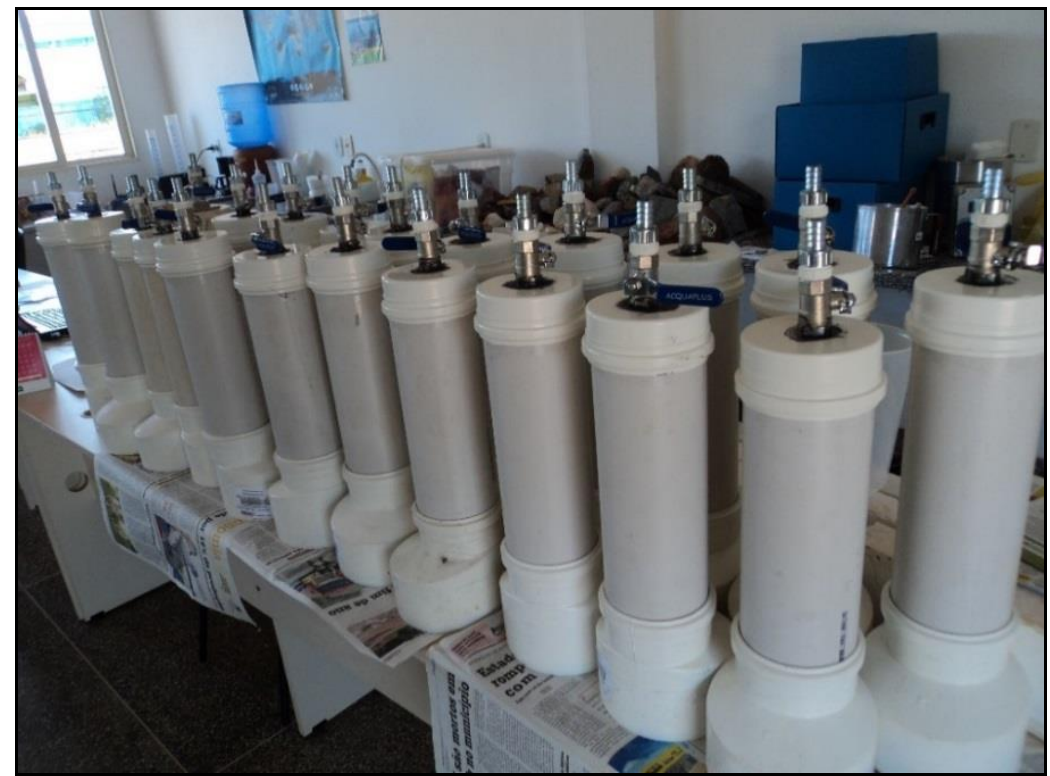

Figura 6 - Cortes e colagem do pluviômetro de PVC

Fonte: SOUSA, R. R., 2016.

Após o processo de confecção dos pluviômetros de PVC, realizou-se o teste de vazamento por 48 horas, no intuito de se houver confiabilidade e credibilidade de armazenamento de água no instrumento (Figura 7).

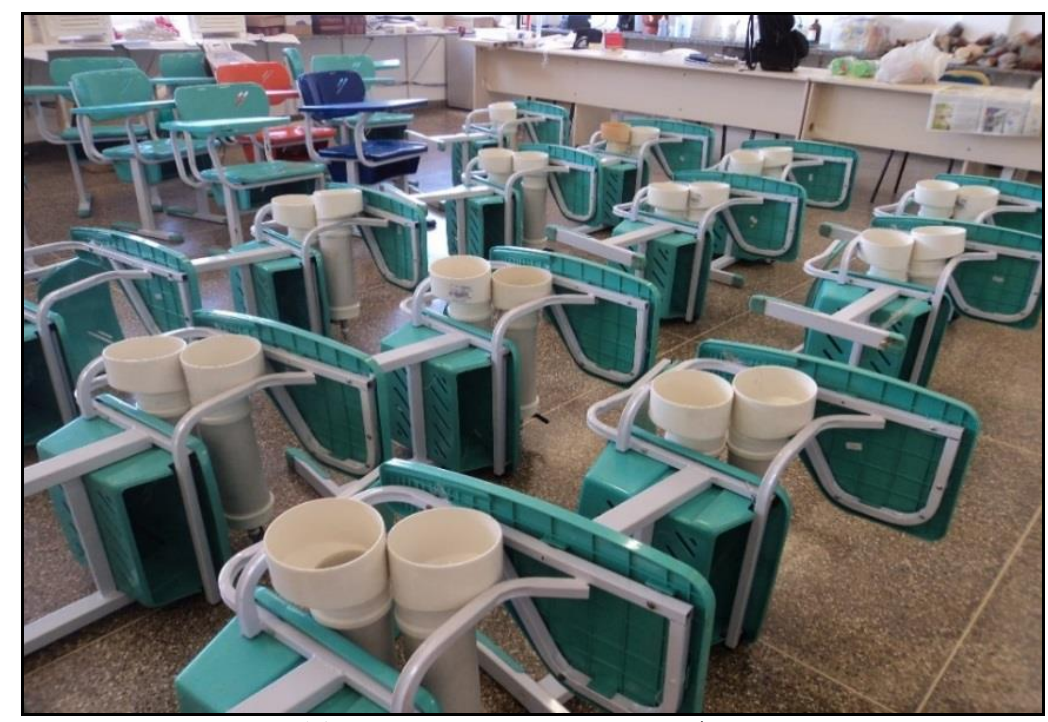

Figura 7 - Teste de vazamento do pluviômetro de PVC

Fonte: SOUSA, R. R., 2016. 
| Pluviômetro de baixo custo e a variação da chuva no município de Barra do Garças - MT (outubro de 2015 a abril de 2016)|

| Romário Rosa de Sousa |

As observações pluviométricas foram feitas com uma proveta graduada de $250 \mathrm{ml}$, convertida para $15 \mathrm{~mm}$ (Figura 8), convertida obedecendo a seguinte fórmula:

$$
H=10 \frac{V}{S}
$$

onde $H$ é a lâmina de chuva $(\mathrm{mm}) ; V$ é o volume de chuva coletado $\left(\mathrm{cm}^{3}\right.$ ou $\left.\mathrm{ml}\right)$ e $S$ é a área de captação da boca do pluviômetro $\left(\mathrm{cm}^{2}\right)$. Teoricamente, este procedimento possui uma precisão similar ao obtido com o pluviômetro padrão "Ville de Paris", que possui uma área de captação de $400 \mathrm{~cm}^{2}$.

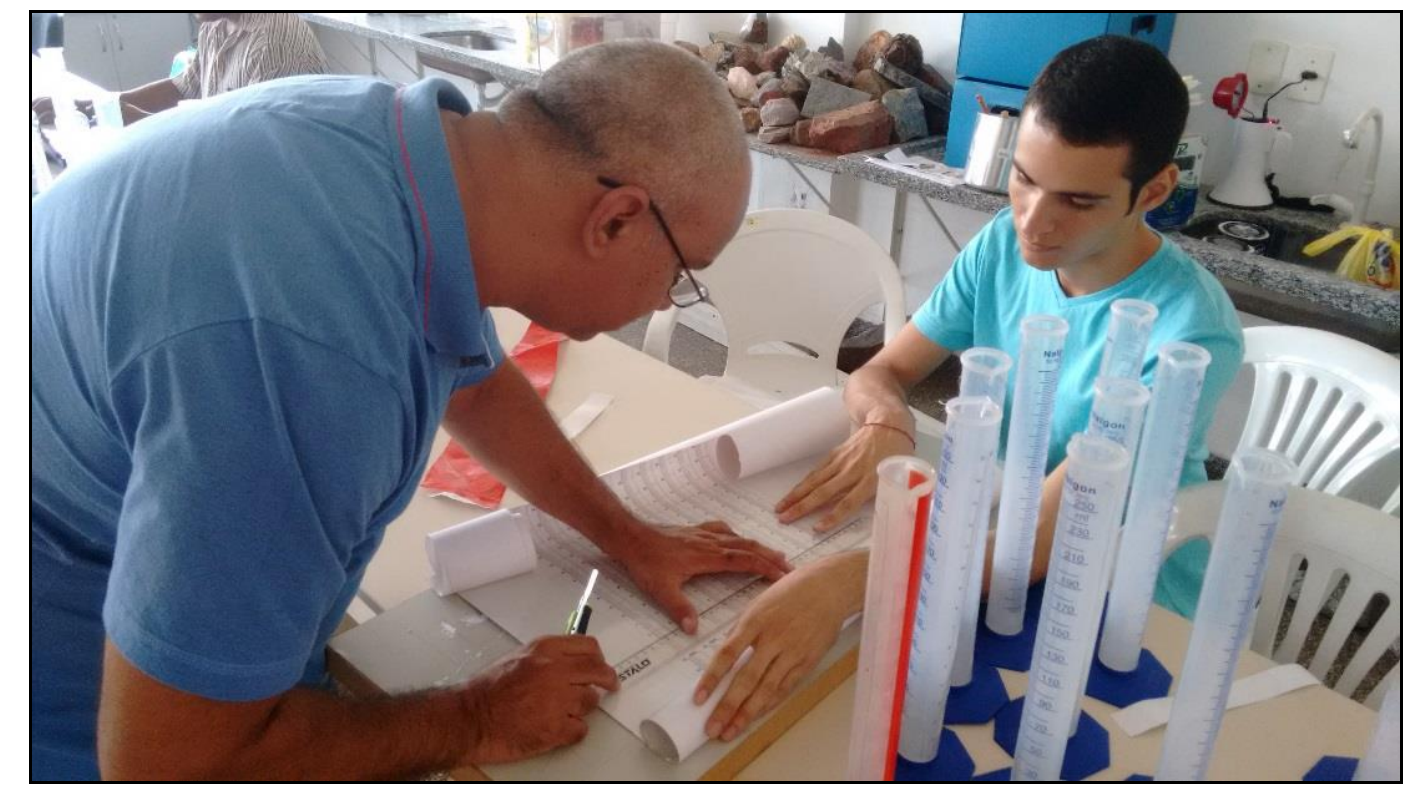

Figura 8 - Processo de colagem da graduação de $250 \mathrm{ml}$ para $15 \mathrm{~mm}$ Fonte: SOUSA, R. R., 2016.

Ainda na fase de montagem dos pluviômetros, procedeu-se a preparação dos mastros de madeira, onde cada em cada foi adaptado com um corte de $45^{\circ}$ graus na parte superior para servir de suporte no momento de fixação do pluviômetro de PVC, a uma medida de 1,50 centímetros do solo (Figura 9). 


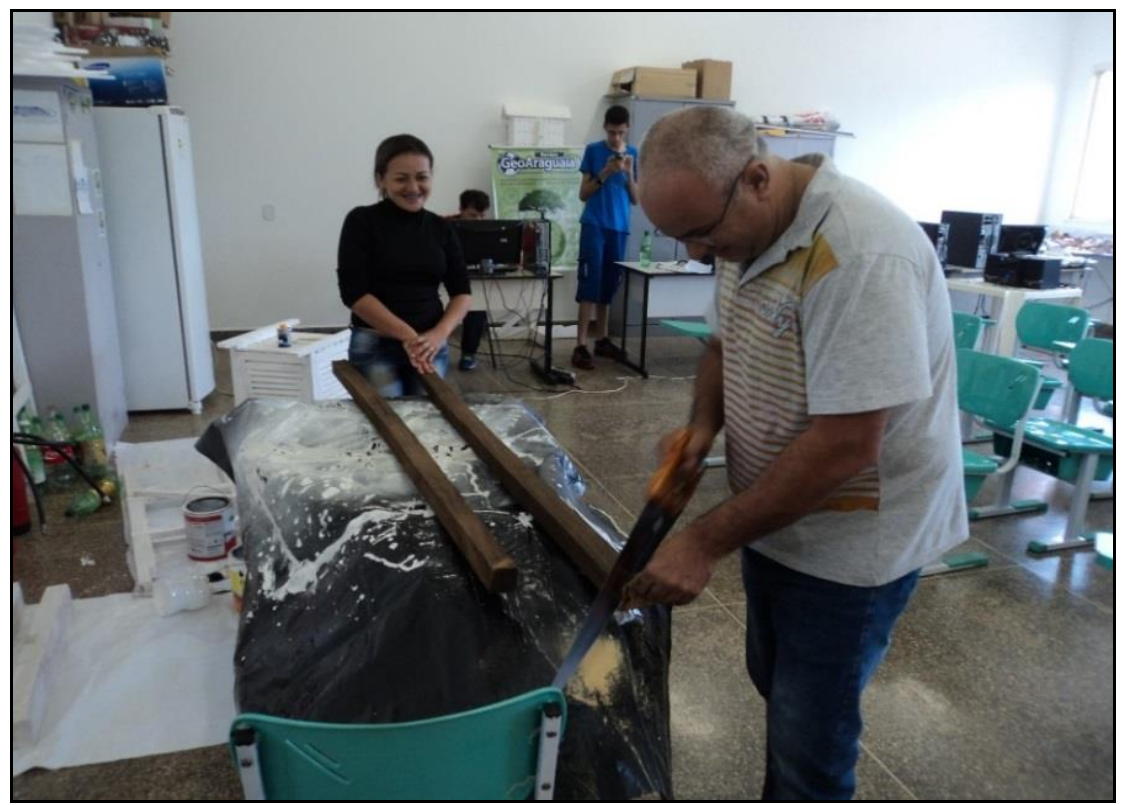

Figura 9 - Processo de preparação do mastro de madeira Fonte: SOUSA, R. R., 2016.

Vale ressaltar que a correlação existente, do pluviômetro de PVC possui uma área de capitação de $\left(78 \mathrm{~cm}^{2}\right)$ e o padrão abrangendo $\left(400 \mathrm{~cm}^{2}\right)$, este encontrado nas estações meteorológicas do INMET (Figuras 10 e 11). As observações foram realizadas nos dois pluviômetros ao mesmo tempo, seguindo os horários determinados da estação meteorológica $10^{\circ}$ DISME/INMET - (Organização Mundial de Meteorologia - OMM).

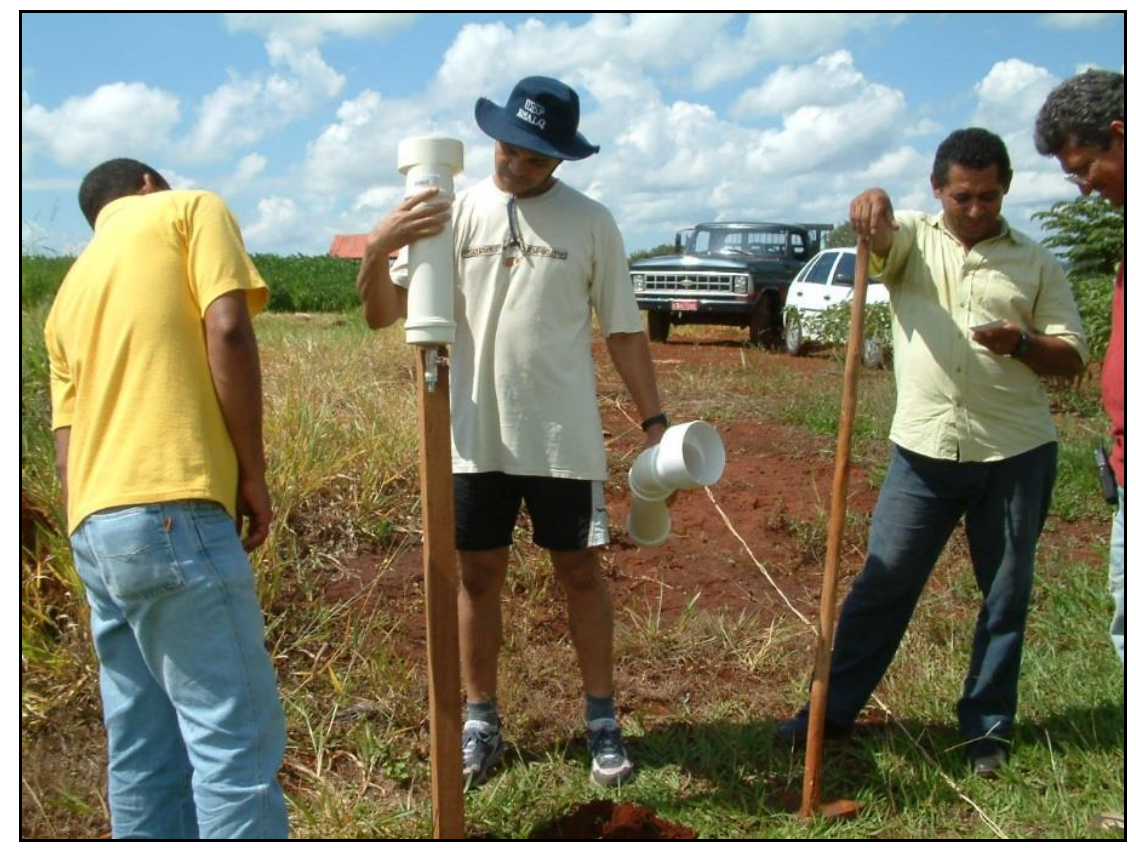

Figura 10 - Processo de instalação pluviômetro de baixo custo na estação Fonte: SOUSA, R. R., 2016. 


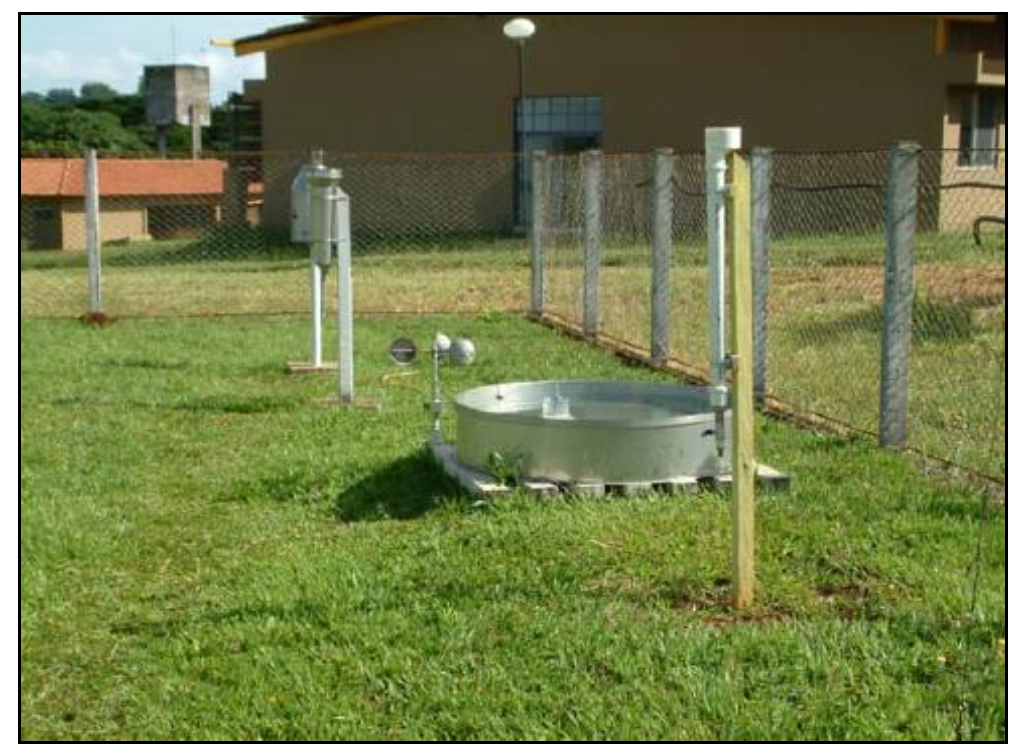

Figura 11 - Processo de aferição e calibração do pluviômetro de baixo custo Fonte: SOUSA, R. R., 2016.

Após toda a coleta e organização dos dados pluviômetros, no período de janeiro de 2016 a março de 2016, sendo este o período chuvoso em nossa região, procederam-se calibração e aferição dos instrumentos. A correlação entre os dados do pluviômetro padrão e os dados do pluviômetro caseiro foi equacionado com a seguinte função: $y=0,9812 x$, com $\mathrm{R}_{2}=0,9898$ (Figura 12). Observando a figura 12, nota-se que a dispersão está próxima do modelo de (reta), sendo de a margem de erro do pluviômetro de PCV e de apenas $0,2 \%$ e mais de 98\% para menos, então 0,9898 da precipitação registrada pelo pluviômetro padrão é também registrado pelo pluviômetro de PCV.

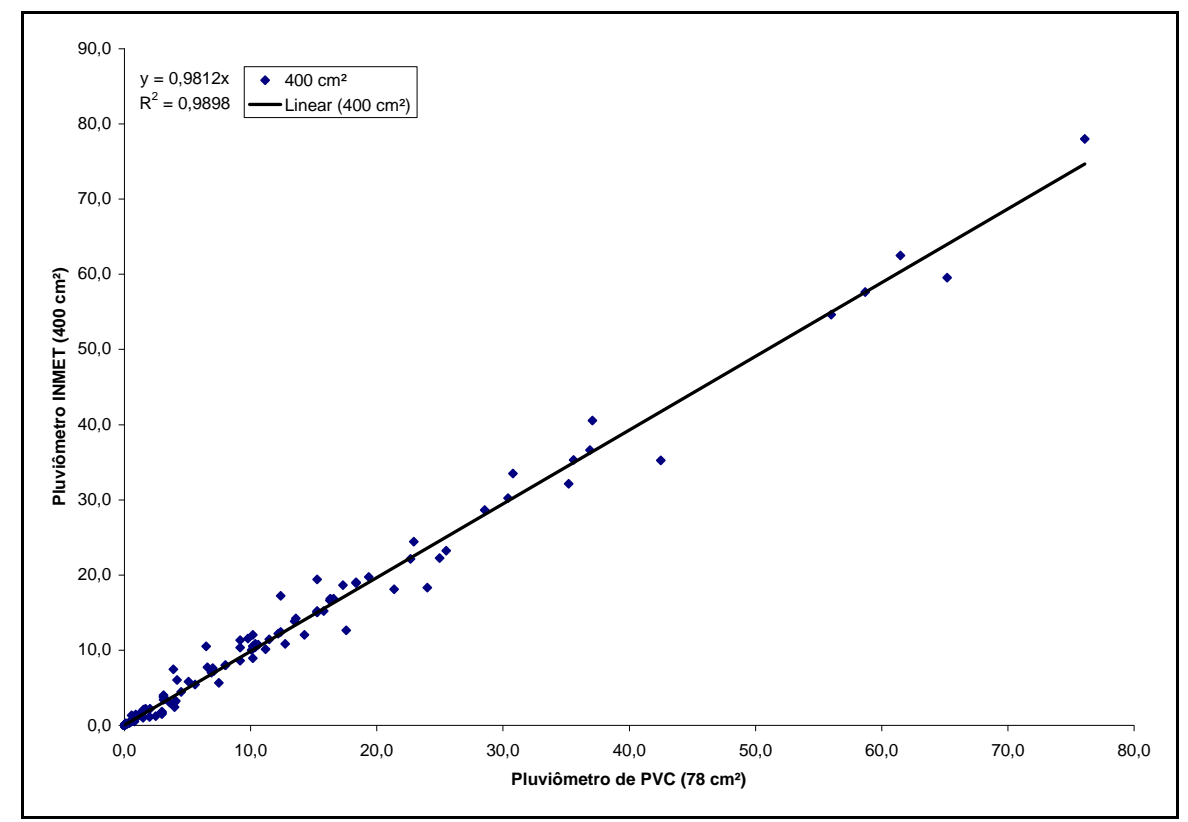

Figura 12 - Comparação do pluviômetro de padrão e do pluviômetro de PVC Organizador: SOUSA, R. R., 2016. 
| Pluviômetro de baixo custo e a variação da chuva no município de Barra do Garças - MT (outubro de 2015 a abril de 2016)|

| Romário Rosa de Sousa |

Depois de todo o processo de aferição dos pluviômetros de PVC, partiu-se para a etapa de campo, onde se constou em fixar os pluviômetros nas propriedades rurais com prévia autorização e treinamento simples das pessoas que ficaram responsáveis por coletar os dados pluviométricos registrados pelo coletor de chuva (Figura 13).

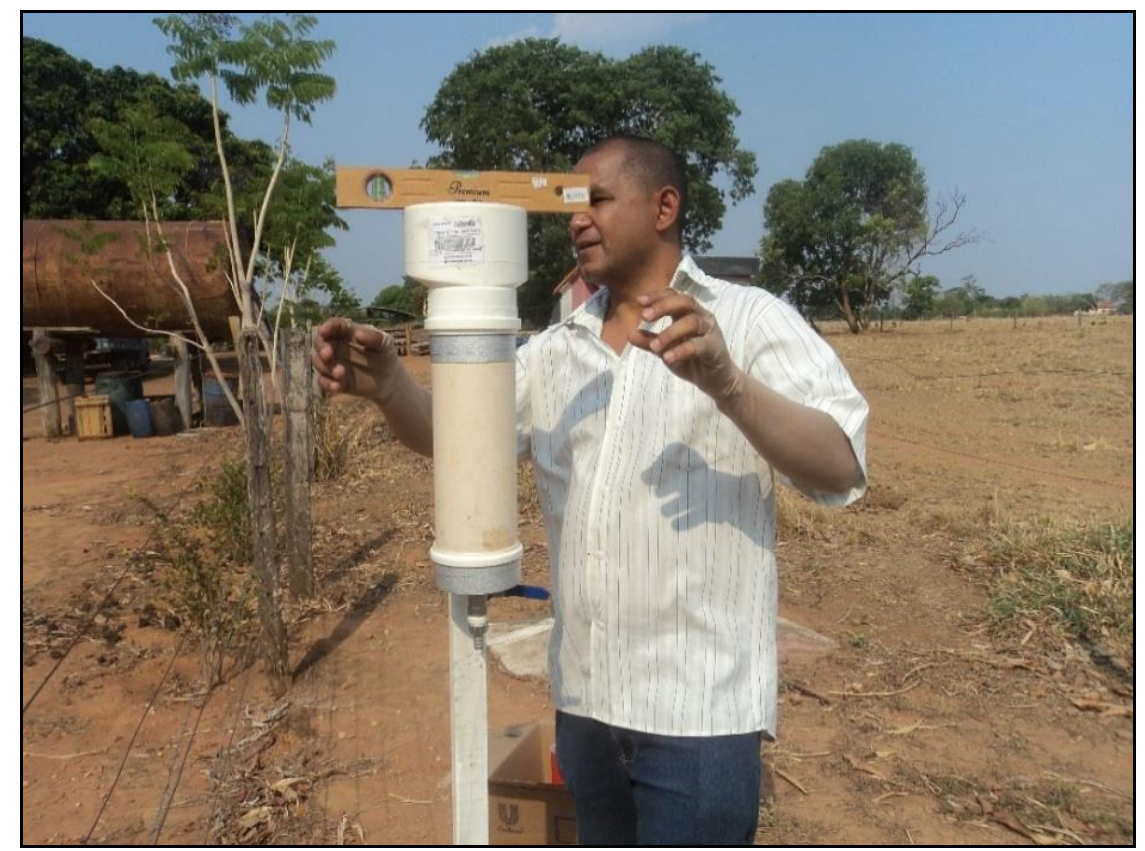

Figura 13 - Instalação do pluviômetro de PVC

Fonte: SOUSA, R. R., 2016.

De acordo com Assad (1994), é fundamental caracterizar a distribuição da precipitação pluviométrica nos Cerrados, tratando os dados disponíveis de chuva mensal, analisando os seus padrões pluviométricos e, principalmente, identificando seus movimentos sazonais. Os valores sazonais mensais são estimativas razoáveis para estudar as variações pluviométricas dos meses durante o ano, para cada série de cada estação pluviométrica analisada.

Após o período chuvoso, referente a outubro de 2015 a abril de 2016, foram recolhidos os dados pluviométricos nos pontos de observação. Com isso, em posse dos dados chuvosos, os mesmos foram organizados em planilha eletrônica para posterior relatório de tabela dinâmica, onde foram extraídas as somatórias pluviométricas de cada ponto específico (Tabela 1), na qual a determinação da distribuição espacial das chuvas dentro do município foi feita pelo método das isoietas no Sistema de Informações Geográficas (SIG), através do software ArcGIS 10.1. 
| Romário Rosa de Sousa |

Tabela 1 - Propriedades rurais com instalação dos pluviômetros

\begin{tabular}{rrlr}
\hline Longitude & Latitude & Local & Precipitação \\
\hline 385811 & 8249446 & Fazenda Ouro Fino & 986,1 \\
348627 & 8253792 & Fazenda Cristo Rei & 369,4 \\
312477 & 8291972 & Fazenda São Bento & 562,2 \\
353971 & 8250390 & Fazenda Escola Univar & 810,4 \\
376569 & 8280513 & Fazenda Paulistinha & 430,0 \\
373330 & 8300218 & Fazenda Santa Eugênia & 271,0 \\
377357 & 8330715 & Fazenda Flôres & 146,2 \\
373545 & 8347855 & Fazenda 2 Ancoras & 559,4 \\
351872 & 8334394 & Fazenda Vale Verde & 962,0 \\
355842 & 8302381 & Fazenda Paraná & 952,1 \\
326497 & 8260408 & Estância Bandeirantes & 769,2 \\
320609 & 8277551 & Fazenda Ipê & 745,7 \\
265084 & 8284928 & Fazenda São Gabriel & 408,2 \\
265643 & 8296333 & Fazenda Morro Alto & 410,7 \\
255331 & 8310333 & Fazenda Sifrão & 745,6 \\
280726 & 8310042 & Fazenda Beira Rio & 553,2 \\
373482 & 8247483 & Sítio Paredão & 890,7 \\
\hline & Organizador: SOUSA, R. R., 2016.
\end{tabular}

$\mathrm{Na}$ tabela 1, notou-se que as propriedades rurais beneficiadas e parceiras do projeto de pesquisa, apresentaram uma irregularidade pluviométrica, sendo algo bem típico da dinâmica climática na área de Cerrado.

Evidenciou-se na figura 14, a distribuição pluviométrica da chuva no município de Barra do Garças-MT, em que se evidenciou ser bem diversificada e irregular para o período estudado. Averiguou-se que o maior acúmulo pluviométrico foi registrado no extremo sul do município, com 986,1 mm de chuva. Em contrapartida, um núcleo seco com um baixo volume de precipitação foi confirmado na porção leste com 146,2 mm de chuva.

Ainda observando o mapa de isoietas (Figura 14), na porção oeste, a chuva foi quantificada com 745,6 mm, mais precisamente na fazenda Sifão. Para a porção norte, os valores pluviométricos também se comportaram de forma irregular com dois núcleos chuvosos e com valores expressivos a partir de 834,4 $\mathrm{mm}$ até $986,1 \mathrm{~mm}$ de chuva. Posteriormente a isso, os valores diminuíram de $834,4 \mathrm{~mm}$ até $422,5 \mathrm{~mm}$ de precipitação na área de estudo. 


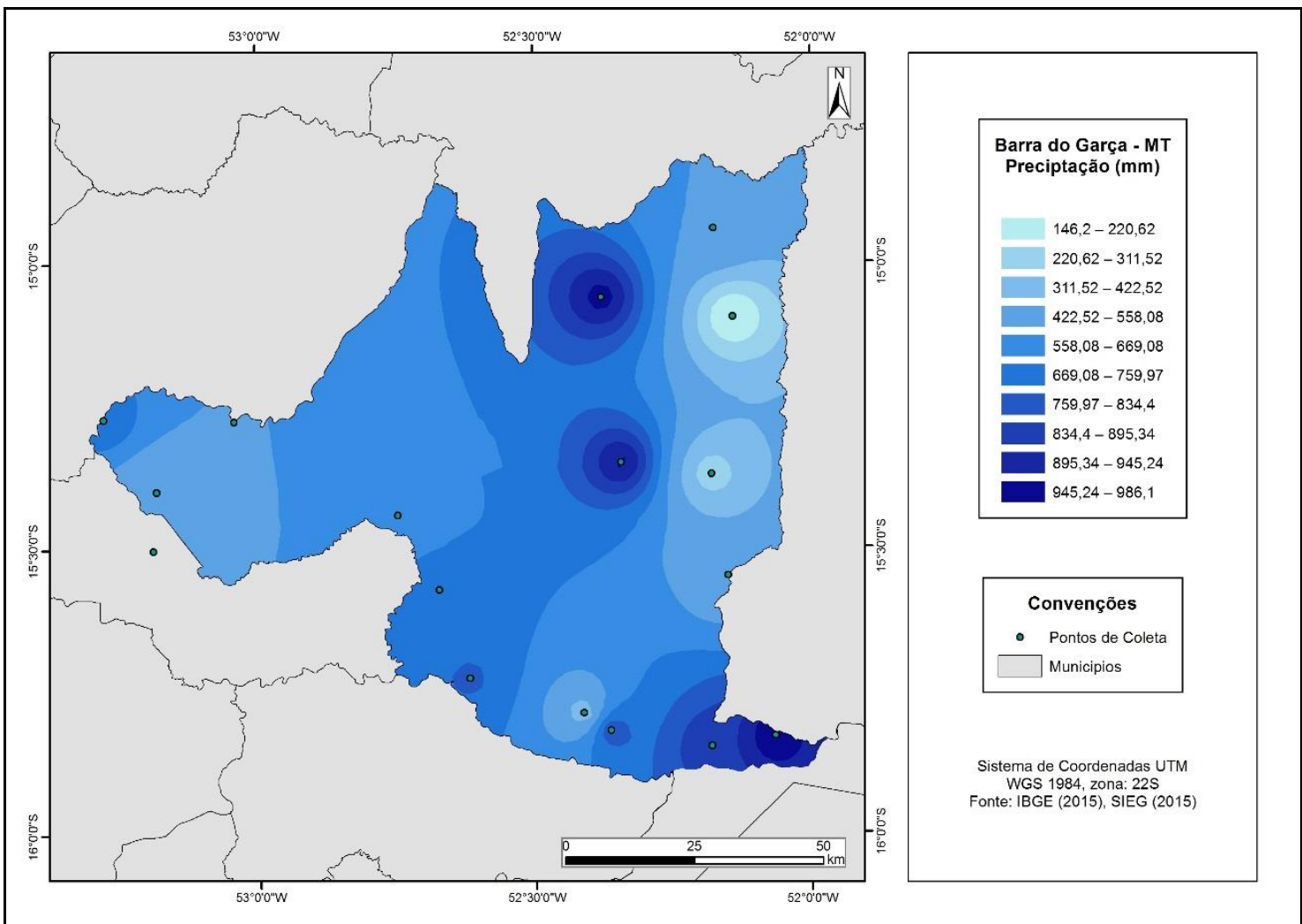

Figura 14 - Limite municipal de Barra do Garças-MT Elaboração: SOUSA, R. R., 2016.

Muitas vezes a distribuição irregular das chuvas atinge as culturas em sua fase reprodutiva, afetando a produção final. Desse modo, o conhecimento da distribuição espacial das chuvas em uma determinada região adquire uma grande importância econômica, uma vez que a sua frequência pode servir de orientação para que os agricultores ajam no sentido de minimizar possíveis reduções na produtividade das culturas (CASTRO, et al. 1994).

Do ponto de vista agro-climatológico, a região dos cerrados está sujeita a regime de secas dentro da estação chuvosa, a qual pode persistir de duas, três semanas ou alcançar até um mês ou mais sem chuvas. Este fenômeno é denominado de veranico (Assad, et al. 1994). Casarim (1983) argumenta que o fenômeno veranico é causado por bloqueios de grande escala no escoamento atmosférico, sendo, desse ponto de vista, o mecanismo do veranico pode estar associado aos deslocamentos da zona de convergência tropical e ao fenômeno "El Nino, diretamente relacionado com o aumento da temperatura do Oceano Pacífico".

\section{CONSIDERAÇÕES FINAIS}


| Pluviômetro de baixo custo e a variação da chuva no município de Barra do Garças - MT (outubro de 2015 a abril de 2016) |

| Romário Rosa de Sousa |

O processo de construção do pluviométrico de baixo custo demonstrou que foi de grande ajuda, no sentido de baixar custos com um instrumento de grande importância para o meio rural e urbano.

Diante da aferição e calibração realizada entre os dois pluviômetros, averiguou-se que o pluviômetro de PVC, é de boa confiabilidade e aceitação. Com isso, o pequeno e médio agricultor tem um bom equipamento de baixo custo para acompanhar a precipitação sua propriedade.

Quanto à variação das chuvas na área estudada, observou-se que as chuvas ocorreram em maior quantidade nas porções Sul e Norte da área de estudos. Enquanto isso, os menores valores estiveram confirmados nas porções Leste e Oeste.

Também é importante ressaltamos a oscilação pluviométrica, que ocorreu ao longo do recorte analisado, em que a chuva apresentou irregularidades durante o período chuvoso (de outubro de 2015 a abril de 2016). Portanto, a chuva foi distribuída de forma irregular durante este período de estudo, onde, em alguns pontos de observação, as precipitações pluviométricas foram acentuadas, e em outros, menos expressivas.

Dessa forma, diante de toda a dinâmica de variabilidade das chuvas atuantes no município de Barra do Garças-MT, é necessária a realização de outros estudos pluviométricos mais detalhados, com outras fontes de dados, e possivelmente uma ampliação da rede de monitoramento, uma vez que os constantes desmatamentos, os cultivos de grãos, mineração e a pecuária têm se destacado localmente como economia, assim, a população tem utilizado o meio físico de uma maneira muitas vezes imprópria.

\section{REFERÊNCIAS}

AB'SABER, A. N.; Costa J. M. Contribuição ao estudo do Sudoeste Goiano. Boletim Paulista de Geografia, São Paulo, v. 4, n. 2, p. 3-26, mar. 1950.

ARAGÃO, M. J. História do clima. Rio de Janeiro: Interciência, 2009.

ASSAD, E. D.; Sano, E. E. Sistema de informações geográficas: aplicações na agricultura. Planaltina: EMBRAPA-CPAC, 1993.

ASSAD, E. D. Chuva nos Cerrados análise e espacialização. Planaltina: EMBRAPACPAC, 1994.

ASSUNÇÃO, H. F.; ASSIS, I. C. Construção de uma mini-estação agroclimatológica de baixo custo. In: X CONGRESSO BRASILEIRO DE AGROMETEREOLOGIA, 10., Piracicaba, 1997. Anais... Campinas: Sociedade Brasileira de Agrometeorologia, 1997. 
| Pluviômetro de baixo custo e a variação da chuva no município de Barra do Garças - MT (outubro de 2015 a abril de 2016)|

| Romário Rosa de Sousa |

AYOADE, J. O. Introdução à climatologia para os trópicos. 20. ed. Rio de Janeiro: Bertrand Brasil, 1988.

CASARIM, D. P. Um estudo observacional sobre os sistemas de bloqueio no hemisfério Sul. In: ASSAD, E. D. (Coord.)., Chuva nos Cerrados: análise e especialização. Brasília: EMBRAPA/CPAC, 1983.

CHANG, K. T. Introduction to Geographic Information Systems. New Delhi: Tata McGraw Hill, 2006. p. 325-327.

CONTI, J. B. Clima e meio ambiente. São Paulo: Atual. 1998.

LOBATO, T. C.; HAUSER-DAVIS, R. A.; OLIVEIRA T. F.; SILVEIRA, A. M.; SILVA, H. A. N.; TAVARES, M. R. M.; SARAIVA, A. C. F. Construction of a novel water quality index and quality indicator for reservoir water quality evaluation: a case study in the Amazon region. Journal of Hydrology, v. 522, p. 674-683, mar. 2015.

MIRANDA, J. I. Fundamentos de sistemas de informações geográficas. 2. ed. Brasília: EMBRAPA Informação Tecnológica, 2005.

MONTEIRO, C. A. F. Notas para o estudo do clima do Centro-Oeste brasileiro. Revista Brasileira de Geografia, Rio de Janeiro, v. 13, n. 1, p. 3-46, 1951.

PEREIRA, A. R.; ANGELOCCI, L. R.; SENTELHAS, P. C. Agrometeorologia: fundamentos e aplicações práticas. Guaíba: Agropecuária, 2002.

SOUZA, J. L. L. L.; GOMES, T. S.; DIAS, R. S.; OLIVEIRA, G. M. A.; SANTOS, R. L. Avaliação de métodos de interpolação aplicados à espacialização das chuvas no território identidade Portal do Sertão/Bahia. In: XV SIMPÓSIO BRASILEIRO DE SENSORIAMENTO REMOTO - SBSR, 15., Curitiba, 2011. Anais... Curitiba: INPE, 2011. p. 4295-4302.

TARIFA, J. R. Alterações climáticas resultantes da ocupação agrícola no Brasil. Revista do Departamento de Geografia, São Paulo, v. 8, p. 15-27. 1994.

TROPPMAIR, H. Biogeografia e meio ambiente. 5. ed. Rio Claro: Divisa, 2002.

VIANELLO, R. L.; MAIA, L. F. P. G. Estudo preliminar da climatologia dinâmica do estado de Minas Gerais. Informe Agropecuário, Belo Horizonte, v. 12, n. 138, p. 6-8, jun. 1986.

VILA, R. C. Os segredos do tempo. Rio de Janeiro: Fundação Getúlio Vargas, 1975.

VILLELA, S. M.; Mattos, A. Hidrologia aplicada. São Paulo: McGraw-Hill do Brasil, 1975. 